\title{
Mechanical Performances of Artificial Aggregated Lightweight Concrete
}

\author{
M. DAVRAZ ${ }^{a, *}$, H. CEYlan ${ }^{b}$, Ş. KilinÇARSLAN ${ }^{a}$ \\ ${ }^{a}$ Natural and Industrial Building Materials Application and Research Centre, \\ Süleyman Demirel University, 32260, Isparta, Turkey \\ ${ }^{b}$ Department of Construction, Technical Sciences Vocation School, \\ Süleyman Demirel University, 32260, Isparta, Turkey
}

\begin{abstract}
In this study, some physical and mechanical performances of artificial aggregated lightweight concretes were compared. Special empirical models were developed to estimate the elasticity modulus of lightweight aggregate concrete (LWAC). Five different natural aggregates and one artificial lightweight aggregate material were used throughout the research. Mixture proportions were kept as constant values in all concrete mixtures. All mixtures were cast into cubic, prismatic and cylindrical concrete standard moulds and they were cured at the same curing conditions. A series of physical and mechanical properties, such as density, compressive strength and elasticity modulus for LWAC were experimentally determined. According to the research findings a few empirical models were statistically developed for estimating the elasticity modulus and Poisson's ratio of LWAC and a new diagram practically to be used for estimating the Poisson's ratio of LWAC was also proposed.
\end{abstract}

DOI: 10.12693 /APhysPolA.127.1246

PACS: $62.20 . \mathrm{dj}$

\section{Introduction}

Lightweight aggregate concretes (LWAC) are known as very attracting concretes because of their good sound and heat insulation properties, reducing the dead load of a structure, well fire resistance and having high freezethawing resistance. As to conventional concretes, their densities are very low. Therefore the use of LWAC could supply important reduction in cross sectional areas for the structural elements in a structure and could improve using the open spaces and apertures [1]. Furthermore, the use of LWAC due to superior insulation properties are becoming widespread day by day to produce walls, flooring and roofing constructions, panel and pre-cast units. To reach the high compressive strength for LWAC, the water/cement ratio of mixtures must be selected as a very low value. In other words, as comparing with same strength of normal weight conventional concretes, cement dosage of structural LWAC is higher than the conventional concretes. For this reason, elasticity modulus of LWAC is lower than the conventional concretes and Poisson's ratio is relatively higher. The effect of aggregate properties on LWAC characteristics has been investigated by different researchers [2-5]. Yang \& Huang stated the effectiveness of aggregate volume and its properties on the compressive strength of concretes [6]. Teychenne and at all investigated the relationship between the elasticity modulus and aggregate properties in normal weight concretes. They showed that aggregate properties are very important fact on elasticity modulus of even normal weight concrete. They also proposed a classification

*corresponding author; e-mail: davrazm@gmail.com system having different three groups to estimate elasticity modulus of concretes [7]. CEB/FIB also suggested an estimation formula for elasticity modulus in relation for only compressive strength of concretes [8]. In this paper, the physical properties of five natural LWA types obtained from different quarries in Turkey and one artificial LWA were analyzed. As to aggregate type, densities, uniaxial compressive strength, flexural strength, static elasticity modulus and Poisson's ratio for LWAC were experimentally analyzed.

\section{Experimental work}

\subsection{Properties of cement and aggregate}

Ordinary Portland cement CEM I 42.5R was used throughout the research in concrete mixtures as a binding material. In control concrete samples, crushed limestone aggregate (CLA) obtained from the aggregate quarry of Isparta Municipality was used as concrete aggregates. Basically six different aggregate types were used in this study to make the LWAC mixtures with cement. These are Isparta Karakaya pumice (IKP), Isparta Gelincik pumice (IGP), Kayseri pumice (KP), Nevşehir pumice (NP), Kula volcanic slag (KVS) as natural LWA and expanded clay aggregate (ECA) as artificial LWA respectively. All aggregates were screened through a square fine sieve and classified into two different size fractions of $0 / 4 \mathrm{~mm}$ and $4 / 8 \mathrm{~mm}$. Properties of aggregates used in this research were given in Table I.

\subsection{Aggregate-concrete mixture designs and preparation of test samples}

Two different granulometric designs for aggregates were used in this study. In the first group of granulometric design, $60 \%$ aggregate amount at $4 / 8 \mathrm{~mm}$ size and $40 \%$ aggregate amount at $0 / 4 \mathrm{~mm}$ size were used 
Properties of normal and LWA used in the concrete mixtures according to TS 699 and TS EN 1097-6 standards [9, 10].

\begin{tabular}{|c|c|c|c|c|c|c|c|c|}
\hline $\begin{array}{l}\text { Aggr. } \\
\text { type }\end{array}$ & $\begin{array}{c}\rho_{r d} \\
{\left[\mathrm{~g} / \mathrm{cm}^{3}\right]}\end{array}$ & $\begin{array}{c}\rho_{a v} \\
{\left[\mathrm{~g} / \mathrm{cm}^{3}\right]}\end{array}$ & $\begin{array}{l}\mathrm{M}_{t} \\
{[\%]}\end{array}$ & $\begin{array}{c}\eta_{1} \\
{[\%]}\end{array}$ & $\begin{array}{c}\eta_{0} \\
{[\%]}\end{array}$ & $\begin{array}{c}\mathrm{c}_{a} \\
{[\%]}\end{array}$ & $\begin{array}{c}\mathrm{c}_{r} \\
{[\%]}\end{array}$ & $\begin{array}{c}\text { CPR } \\
{[\%]}\end{array}$ \\
\hline $\mathrm{CLA} 4 / 8$ & 2.576 & 2.771 & 2.723 & 7.032 & 7.014 & 92.968 & 92.986 & 0.018 \\
\hline $\mathrm{CLA} 0 / 4$ & 2.723 & 2.771 & 0.209 & 1.729 & 0.569 & 98.271 & 99.431 & 1.160 \\
\hline $\mathrm{IKP} 4 / 8$ & 1.071 & 2.577 & 43.443 & 58.426 & 46.548 & 41.574 & 53.452 & 11.878 \\
\hline IKP0 $/ 4$ & 1.489 & 2.577 & 28.327 & 42.229 & 42.177 & 57.771 & 57.823 & 0.052 \\
\hline $\mathrm{IGP} 4 / 8$ & 0.665 & 2.489 & 77.817 & 73.263 & 51.778 & 26.737 & 48.222 & 21.485 \\
\hline IGP0/4 & 1.287 & 2.489 & 35.165 & 48.278 & 45.264 & 51.722 & 54.736 & 3.015 \\
\hline $\mathrm{KP} 4 / 8$ & 0.709 & 2.407 & 55.860 & 70.526 & 39.624 & 29.474 & 60.376 & 30.903 \\
\hline $\mathrm{KP} 0 / 4$ & 0.855 & 2.407 & 57.322 & 64.469 & 49.019 & 35.531 & 50.981 & 15.450 \\
\hline NP4/8 & 0.858 & 2.311 & 26.839 & 62.874 & 23.024 & 37.126 & 76.976 & 39.851 \\
\hline $\mathrm{NP0} / 4$ & 1.252 & 2.311 & 19.032 & 45.799 & 23.835 & 54.201 & 76.165 & 21.964 \\
\hline $\mathrm{KVS} 4 / 8$ & 1.778 & 2.808 & 10.480 & 36.695 & 18.631 & 63.305 & 81.369 & 18.064 \\
\hline $\mathrm{KVS} 0 / 4$ & 2.021 & 2.808 & 10.629 & 28.032 & 21.481 & 71.968 & 78.519 & 6.550 \\
\hline $\mathrm{ECA} 4 / 8$ & 1.180 & 2.519 & 11.659 & 53.152 & 13.758 & 46.848 & 86.242 & 39.394 \\
\hline $\mathrm{ECA0} / 4$ & 1.243 & 2.519 & 26.694 & 50.652 & 33.181 & 49.348 & 66.819 & 17.471 \\
\hline
\end{tabular}

throughout the research. In the second group of granulometric design, $60 \%$ aggregate amount at $0 / 4 \mathrm{~mm}$ size and $40 \%$ aggregate amount at $4 / 8 \mathrm{~mm}$ size were used in the mixtures too. Granulometric curves of group I and II of aggregates was given in Fig. 1. Totally fourteen different concrete mixtures were prepared to compare the me-
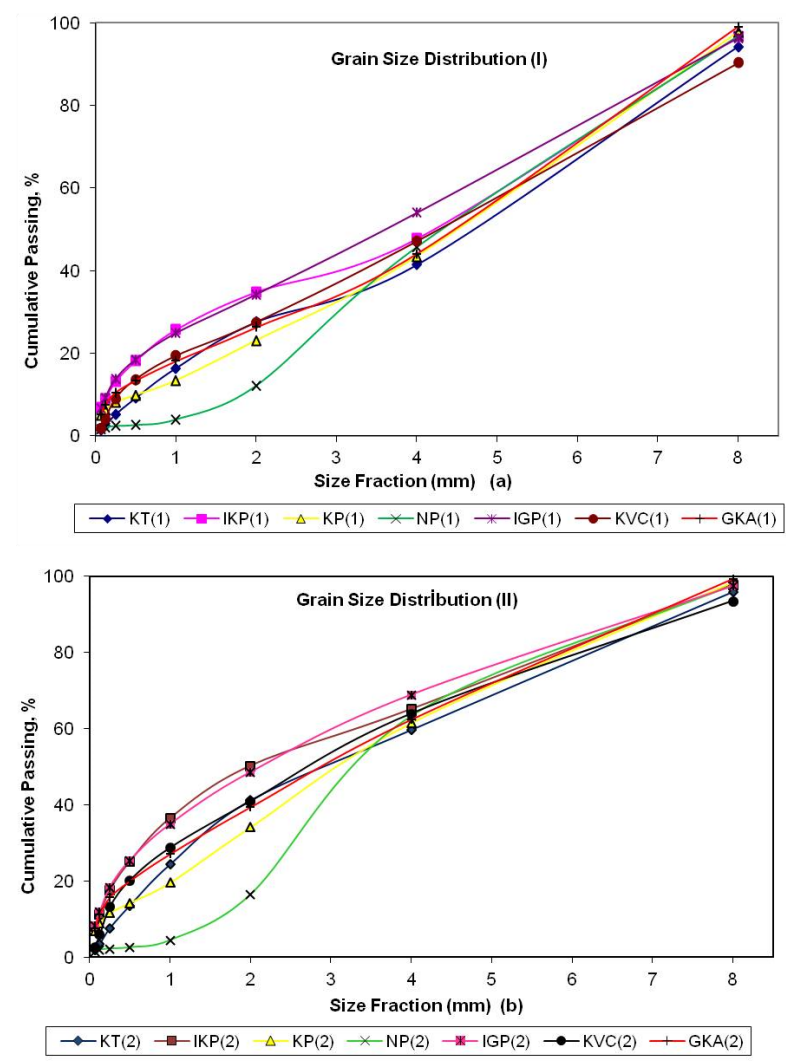

Fig. 1. Granulometric curve of the aggregates (aGroup I group, b-Group II). chanical properties of concrete samples made by normal aggregate and LWA having two different granulometric designs. The mixture proportions were given in Table II.

Concrete mixture designs for the nor-

TABLE II mal and LWA.

\begin{tabular}{c|c|c|c|c|c|c}
\hline \hline $\begin{array}{c}\text { Con- } \\
\text { crete } \\
\text { code }\end{array}$ & $\begin{array}{c}\text { Ce- } \\
\text { ment } \\
{[\mathrm{kg}]}\end{array}$ & $\begin{array}{c}\text { Water } \\
{[\mathrm{kg}]}\end{array}$ & $\begin{array}{c}\text { Course agg. } \\
(4 / 8 \mathrm{~mm}) \\
{[\mathrm{kg}]}\end{array}$ & $\begin{array}{c}\text { Fine agg. } \\
(0 / 4 \mathrm{~mm}) \\
{[\mathrm{kg}]}\end{array}$ & $\begin{array}{c}\text { S. plasti- } \\
\text { cizer } \\
{[\mathrm{kg}]}\end{array}$ & $\begin{array}{c}\rho_{\text {conc }} \\
{\left[\mathrm{kg} / \mathrm{m}^{3}\right]}\end{array}$ \\
\hline NC I & 400 & 160 & 1058 & 746 & 8 & 2.372 \\
LC I & 400 & 160 & 440 & 408 & 8 & 1.416 \\
IGP I & 400 & 160 & 273 & 352 & 8 & 1.194 \\
KP I & 400 & 160 & 291 & 234 & 8 & 1.093 \\
NP I & 400 & 160 & 352 & 343 & 8 & 1.263 \\
KVS I & 400 & 160 & 730 & 553 & 8 & 1.852 \\
ECA I & 400 & 160 & 485 & 340 & 8 & 1.393 \\
NC II & 400 & 160 & 705 & 1118 & 8 & 2.392 \\
LC II & 400 & 160 & 293 & 612 & 8 & 1.473 \\
IGP II & 400 & 160 & 182 & 529 & 8 & 1.279 \\
KP II & 400 & 160 & 194 & 351 & 8 & 1.113 \\
NP II & 400 & 160 & 234 & 514 & 8 & 1.317 \\
KVS II & 400 & 160 & 487 & 830 & 8 & 1.885 \\
ECA I & 400 & 160 & 323 & 511 & 8 & 1.402 \\
\hline
\end{tabular}

Before preparing the concrete mixtures, LWA were tried to be having saturated-dry surface with adding water in rate of their 24 hours water absorptions by weight. Twelve cube samples in $150 \mathrm{~mm}$ size were cast for each mixture to analyze the uniaxial compressive strength and three prismatic concrete samples in $100 \times 100 \times 350 \mathrm{~mm}$ size were also cast for determining the flexural strength of concrete. In addition, three cylindrical samples in $150 \times 300 \mathrm{~mm}$ size were also prepared for determining static elasticity modulus and Poisson's ratio of each concrete group. In all mixture proportions, water/cement $(\mathrm{w} / \mathrm{c})$ ratio of $0 / 4$, cement dosage of $400 \mathrm{~kg} / \mathrm{m}^{3}, 68.45 \%$ of aggregate content by volume and $2 \%$ air content were kept as constant values. Superplasticizer based on polycarboxylic ether was also added as an amount of $2 \%$ of cement weight to reduce water content of concrete mixtures. Concrete samples were extracted after 24 hours from the moulds and they were kept in thermostatic curing water tanks until the testing time.

\subsection{Mechanical testing applied}

Oven dry bulk density of concrete samples with normal and LWA was determined according to the principals of TS EN 12390-7 standard [11]. The uniaxial compressive strength tests were carried out at 3,7 and 28 days curing time on $150 \mathrm{~mm}$ cube samples in accordance with TS EN 12390-3 standard [12]. The flexural strength tests were also carried out only at 28 days curing time on 100x100x350 mm prismatic samples in accordance with TS EN 12390-5 standard [13].

Static elasticity modulus and Poisson's ratio of $150 \times$ $300 \mathrm{~mm}$ in size of concrete samples cured at 28 days were determined according to the principles of TS 3502 standard [14]. This correlation was calculated with the Eq. 1, Eq. 2, Eq. 3 and Eq. 4. 


$$
\begin{aligned}
& \varepsilon_{x 1}=\frac{\Delta L_{1}}{L_{0}} \text { and } \varepsilon_{x 2}=\frac{\Delta L_{2}}{L_{0}}, \\
& E=\frac{\sigma_{2}-\sigma_{1}}{\varepsilon_{X 2}-\varepsilon_{X 1}}, \\
& \varepsilon_{y 1}=\frac{\Delta d_{1}}{d_{0}} \text { and } \varepsilon_{y 2}=\frac{\Delta d_{2}}{d_{0}}, \\
& \nu=\left(\frac{\varepsilon_{y 2}-\varepsilon_{y 1}}{\varepsilon_{x 2}-\varepsilon_{x 1}}\right) .
\end{aligned}
$$

Where;

$E$ : (Secant) Elasticity Modulus, (MPa),

$\sigma_{1}$ : Initial strength value, $(\mathrm{MPa})$,

$\sigma_{2}$ : Boundary strength value, (MPa),

$\varepsilon_{x 1}$ : Axial deformation corresponding to initial strength,

$\varepsilon_{x 2}$ : Axial deformation corresponding to boundary strength,

$L_{0}$ : Initial length of concrete sample, $(\mathrm{mm})$,

$L_{2}$ : Value of length change at initial strength, $(\mathrm{mm})$,

$L_{1}$ : Value of length change at boundary strength, $(\mathrm{mm})$,

$\nu$ : Poisson's ratio,

$d_{0}$ : Initial diameter of concrete sample, $(\mathrm{mm})$,

$\Delta d_{2}$ : Value of diameter change at initial strength, $(\mathrm{mm})$,

$\Delta d_{1}$ : Value of diameter change at boundary strength, $(\mathrm{mm})$.

The lateral deformations $\left(\varepsilon_{y 1}\right.$ and $\left.\varepsilon_{y 2}\right)$ in equivalent to the initial and boundary strengths were calculated with the relation in Eq. 4. These deformations were also processed in abscissa of graphical presentation and the strengths were processed in ordinates of the graphic. The slope of line in tangent with the curve obtained was evaluated as (secant) Poisson's Ratio.

\section{Results and discussion 3.1. Density}

As evaluating the densities of LWAC samples according to TS EN 206-1 standard [15], it was observed that;

- KP I, NP I, KP II and NP II (LWAC) samples are related to class of D1.2, - IGP I, ECA I, IGP II, ECA II and IKP I (LWAC) samples are related to class of D1.4, - IKP II, KVS I (LWAC) samples are related to class of D1.6, and - KVS II (LWAC) samples are related to class of D1.8 in density classification.

The change of hardened LWAC density in equivalence the mixture proportions of control concrete was given in Fig. 3. The density of concrete samples prepared with Nevşehir and Kayseri pumice aggregates is about to $50 \%$ of the control concrete in both groups.

\subsection{Uniaxial compressive strength}

The uniaxial compressive strength values based on curing time for the control and LWAC samples were given in Fig. 2. As evaluating the average $\sigma_{L W C} / \sigma_{\text {cont }}$ ratio at 28 days of curing, this ratio is about to $44 \%$ of first group of samples and it was also observed that this ratio increases up to $59 \%$ for the second group. This state, especially development of strength increase against to normal concrete, represents that the granulometric designs of the second group of LWAC are more suitable to concrete mixture proportions. In addition, characteristic compressive strength values of lightweight concrete samples at 28 days curing time were interpreted in accordance with TS EN 206-1 standard [15]. The basic research evaluation is as follows:

- KP I, NP I and KVS I (LWAC) samples prove the lowest strength class of LC9 mentioned in the standard, IKP I, IGP I and ECA I (LWAC) samples also prove the strength class of LC9 mentioned in the standard, - IKP II, IGP II, KP II, NP II and KVS II (LWAC) samples prove the strength class of LC13, and - ECA II (LWAC) samples prove the strength class of LC18.
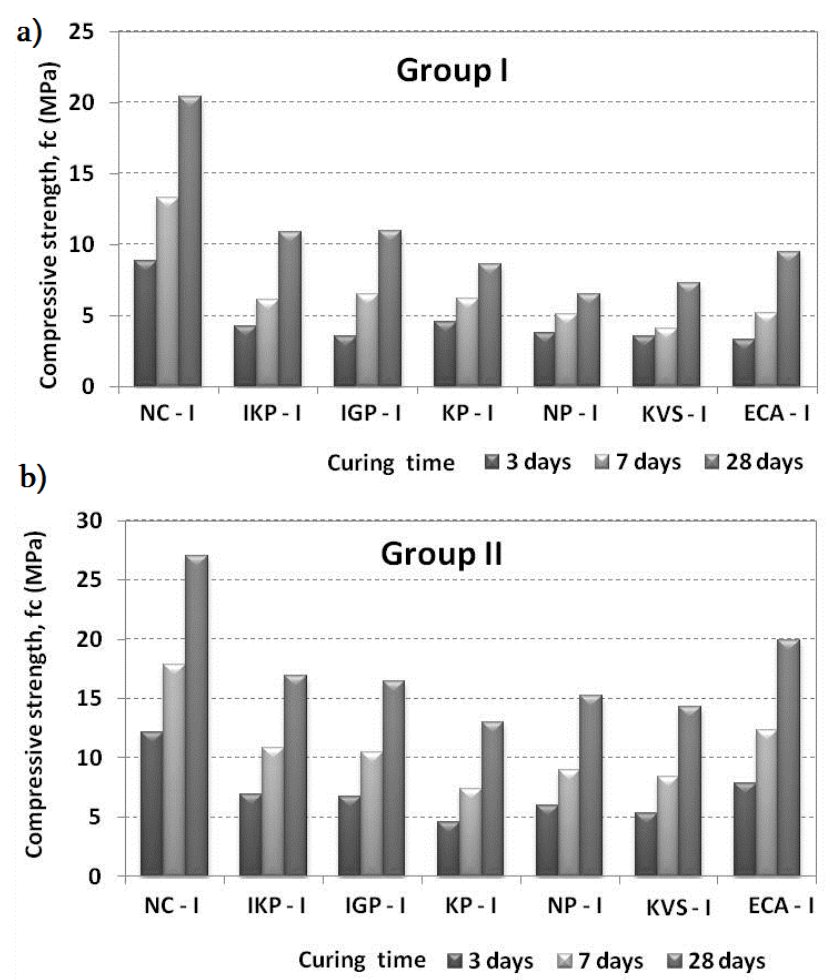

Fig. 2. Strength values of control and LWAC samples based on curing time.

\subsection{Flexural strength}

The flexural strength values at 28 days of curing time for the control and LWAC samples were given as a graphical representation in Fig. 3. Although the flexural strength value of LWAC samples is up to $56 \%$ of flexural strengths for the control concrete samples in taking part of the same granulometric design.

\subsection{Static elasticity modulus and poisson's ratio}

Static elasticity modulus and Poisson's ratio of control and lightweight concrete samples at 28 days of curing time were given in Table III. The elasticity modulus of 

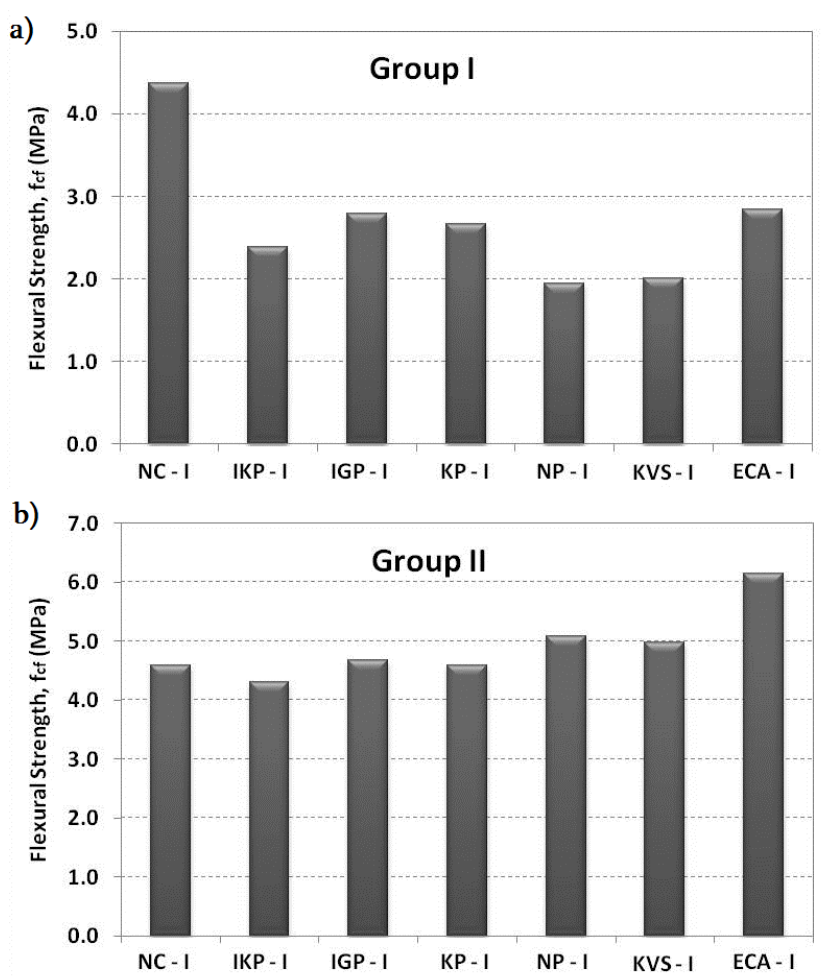

Fig. 3. Flexural strength values of control and LWAC samples based on curing time.

LWAC was ranged between 2.29 to $4.45 \mathrm{GPa}$. The results obtained from this research show a harmony for the values notifying the Gunduz and Ugur's research [16]. As comparing the elasticity modulus of control and LWAC values, $\mathrm{E}_{L W C} / \mathrm{E}_{\text {cont }}$ ratio was a range of $1 / 10$ to $1 / 5$ for the concrete samples. Balendran indicated an approach for comparing the elasticity modulus between the LWAC samples made by expanded clay aggregates and normal sand and limestone aggregated normal concrete mixtures in his research. According to this research, it was stated that elasticity modulus of LWAC is ranged up to $55 \%$ to $70 \%$ of normal concrete's one [4]. Representing the higher values for $\mathrm{E}_{L W C} / \mathrm{E}_{\text {cont }}$ ratio based on Balendran's work is to be leaned by using normal sand as fine aggregates. The strength and deformation characteristics of control and LWAC samples were given in Fig. 4. As evaluating the research results, it was observed that $\sigma_{L W C \text {-max }} / \sigma_{\text {contr-max }}$ ratio is $40 \%$ to be an average value. Against this strength ratio, $\varepsilon_{L W C} / \varepsilon_{\text {cont }}$ ratio in axial deformations is an average of 2.7 . This ratio is also around the average value of 4.4 for lateral deformations. In order to estimate the static elasticity modulus of LWAC samples, a statistical non-parametric regression was developed in this work based on concrete strength and density values. The regression model developed was illustrated in Eq. 5. In order to estimate the static Poisson's ratio of LWAC samples, a statistical non-parametric regression was also developed based on concrete strength and density values. The regression
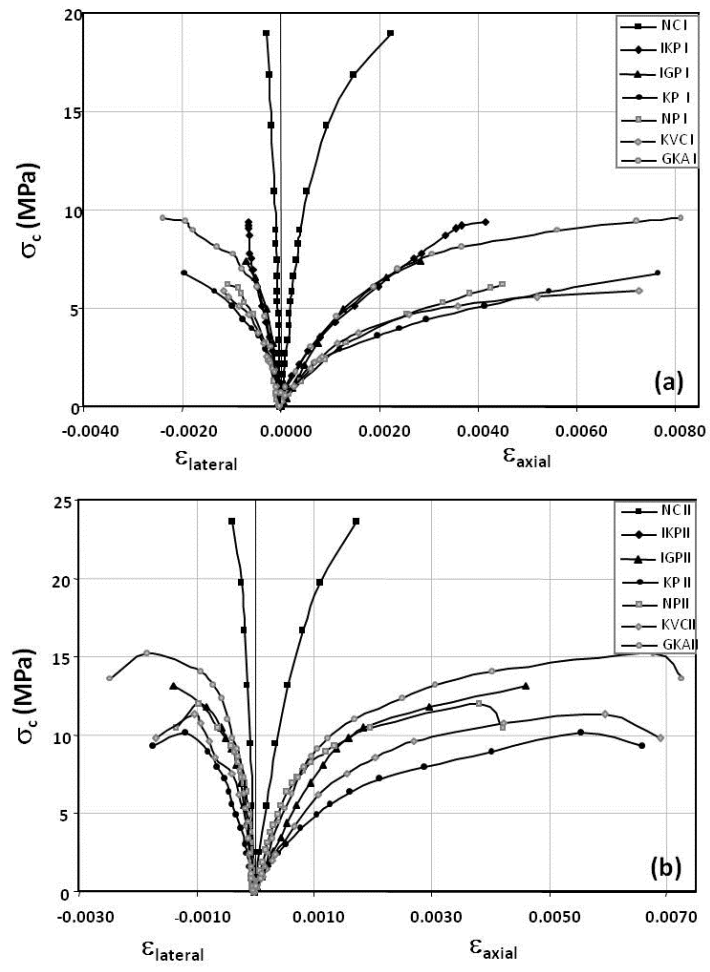

Fig. 4. Strength and deformation characteristics of control and LWAC samples (a-Group I, b-Group II).

model developed was given in Eq. 6 .

$$
\begin{aligned}
& E_{s}=\left[\left(0.011 f_{c k}^{2} \sqrt{D}+\left(0.178 f_{c k} \sqrt[4]{D}\right)+0.644\right],\right. \\
& v=\left[0.171 \ln \left(f_{c k} \frac{D}{E_{s}}\right)+0.0054\right] .
\end{aligned}
$$

Where; $E_{s}$ : Static elasticity modulus of LWAC at 28 days of curing time, $(\mathrm{GPa}), f_{c k}$ : Characteristic compressive strength of LWAC at 28 days of curing time, (MPa), $D$ : Density of LWAC, $(\mathrm{kg} / \mathrm{m} 3), v$ : Static Poisson's ratio of LWAC at 28 days of curing time.

In addition to Eq. 5 and Eq. 6, a diagram was also developed as practical applications to determine the Poisson's ratio based on knowing at least one of physical and mechanical properties for LWAC. This diagram was given in Fig. 5 and it can be used as a template.

Static elasticity Modulus and Poisson's ratio values of control and LWAC samples at 28 days

TABLE III of curing time.

\begin{tabular}{c|c|c|c|c|c|c|c|c|c|c|c|c|c|c}
\hline \hline Sample & NC I & IKP I & IGP I & KP I & NP I & KVS I & ECA I & NC II & IKP II & IGP II & KP II & NP II & KVS II & ECA II \\
\hline $\mathrm{E}_{s}(\mathrm{GPa})$ & 23.35 & 4.01 & 4.45 & 4.14 & 2.29 & 2.34 & 3.82 & 25.64 & 8.31 & 7.87 & 5.01 & 7.03 & 6.36 & 10.13 \\
$\nu_{s}$ & 0.20 & 0.27 & 0.23 & 0.24 & 0.21 & 0.27 & 0.21 & 0.18 & 0.23 & 0.22 & 0.23 & 0.20 & 0.23 & 0.21
\end{tabular}


This diagram could be used for only the following conditions; - Compressive strength of LWAC is at most LC25 and the lower strengths, - Density class must be as $1.2 \leq D \leq 1.8$, - Static elasticity modulus must be of $\leq 14 \mathrm{GPa}$, - Concrete mixture must not contain any gravel aggregate, sand, mineral additive and fibre, - Maximum size fraction of LWA must be $\leq 8 \mathrm{~mm}$ and cement need to be (Portland) CEM I 42.5 R type.

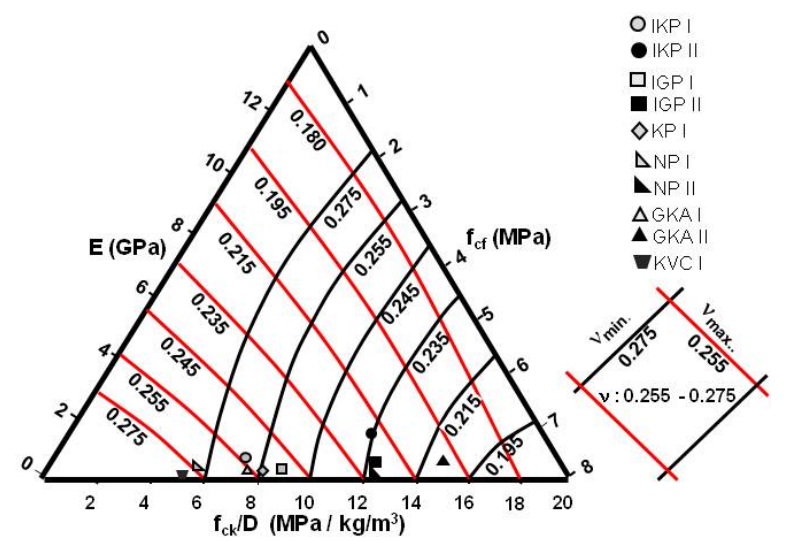

Fig. 5. Poisson's ratio diagram for the use of practical applications of LWAC.

\section{Conclusions}

According to research findings, the following conclusions were given as summary;

- LWAC samples made by Nevşehir and Kayseri pumice aggregates show the lowest concrete densities for both two different granulometric designs. Density of these LWAC samples is approximately $50 \%$ of the control concrete's density. LWAC having highest densities are belongs to the second group of granulometric design with Kula volcanic slug aggregates. Density of these LWAC samples is up to $75 \%$ of the control concrete's density.

- LWAC samples made by natural LWA display to similar mechanical properties. However, a clear improvement for the mechanical performance of the second group of concrete samples was experienced against to the first group of concrete samples.

- The best mechanical properties of LWAC were obtained on the concrete made with using expanded clay aggregates of the second group. These samples show $75 \%$ of compressive strength, $134 \%$ of flexural strength and $40 \%$ secant elasticity modulus of control concrete. According to the control concrete, the nearest Poisson's ratio value was determined at the concretes which produced from expanded clay aggregates $\left(\nu_{s}=0.211\right)$ and Nevsehir pumice aggregates $\left(\nu_{s}=0.203\right)$, among LWAC samples.

- Axial deformations at a maximum strength of the first group LWAC samples showed three times of the control concrete's. On the other hand, this state was observed two times lesser than the second group of the LWAC. Similar subject was also observed in question for lateral deformations. Lateral deformations at a maximum strength of the first group LWAC samples showed four times than the control concrete's. This reduction is 2.3 times of the second group of the LWAC. It is relatively concluded that the second group of LWAC granulometric design indicates an elasto-plastic mechanical characteristic. On the other hand, first group of LWAC granulometric design also indicates as elastic behavior.

- On behalf of the research findings, two empirical models to estimate the static elasticity modulus and Poisson's ratio of LWAC were proposed. In addition, a diagram for practically estimating the Poisson's ratio of LWAC was also developed as a template.

\section{References}

[1] S.C. Kok, Z. Min-Hong, Cement and Concrete Research 25, 276 (2002).

[2] W. Baalbaki, ACI Matter 88, 499 (1991).

[3] G. Giacco, ACI Matter 89, 242 (1992).

[4] R.V. Balendran, Structural Survey 2, 16 (1995).

[5] A.U. Nilsen, Cement and Concrete Research 25, 276 (1995).

[6] C.C. Yang, R. Huang, Cement and Concrete Research 26, 1567 (1996).

[7] D.C. Teychenne, L.J. Parrot, C.D. Pomeroy, Building Research Establishment, Garston, March, 11, 1978.

[8] CEB/FIP (European Committee for Concrete/International Federation of Prestressed Concrete), International recommendations for the design and construction of concrete structures, Cement \& Concrete Association, London 1970.

[9] TS 699/T1, Methods of testing for natural building stones, TSE, Ankara 2000.

[10] TS EN 1097-6, Tests for mechanical and physical properties of aggregates - Part 6: Determination of particle density and water absorption, TSE, Ankara 2002.

[11] TS EN 12390-7, Testing hardened concrete - Part \%: Density of hardened concrete, TSE, Ankara 2002.

[12] TS EN 12390-3, Testing hardened concrete - Part 3: Compressive strength of test specimens, TSE, Ankara 2003.

[13] TS EN 12390-5, Testing hardened concrete - Part 5: Flexural strength of test specimens, TSE, Ankara 2002.

[14] TS 3502, Test method for static modulus of elasticity and Poisson's ratio of concrete in compression, TSE, Ankara 1981.

[15] TS EN 206-1, Concrete - Part 1: Specification performance, production and conformity, TSE, Ankara 2002.

[16] L. Gunduz, I. Ugur, Cement and Concrete Research 35, 1859 (2004). 